\title{
A Brief Discussion on the Cultivation Approaches of Civilized Values in Yunnan Higher Vocational College Student
}

\author{
Wen Zhou ${ }^{1}$ and Boru Yang ${ }^{2^{*}}$ \\ 1.Yunnan College of Foreign Languages and Foreign Affairs, Kunming, Yunnan 651700,china \\ 2.Yunnan College of Foreign Languages and Foreign Affairs, Kunming, Yunnan 651700,china
}

Keywords: Higher vocational college; Civilization value; Approach

\begin{abstract}
On May 5, 2014, general secretary Xi Jinping called on the youth to conscientiously practice the socialist core values in his speech at the symposium of teachers and students of Peking University. As Yunnan province is located in the southwest of China, the unique geographical conditions and national cultural relics determines the unique characteristics of higher vocational college students in Yunnan. Promoting in the higher vocational college students and the cultivation of the humanistic values is imperative, to cultivate a new generation of skilled talents in our country, the realization of "my" China dream "of" solid foundation. So it's imperative to promote the humanistic values and cultivate a new generation of skilled talents for the higher vocational college students.
\end{abstract}

\section{Analysis of Development Status of Yunnan Vocational Students}

\section{Yunnan Attaches Great Importance to the Development of Vocational Colleges}

Yunnan provincial party committee, provincial government attaches great importance to the development of vocational education, carry out the work as a further 18 third, plenary meeting spirit, the implementation of the national medium and long-term education reform and development plan outline (2010-2020) and the state council about accelerate the development of modern vocational education decision "of the important work to grasp, people's livelihood by deepening education" management review "in the field of separation, the vocational schools adhere to the" Khalid ents as fundamental, to serve the development for the purpose, in order to promote the employment as the guidance ", school scale, structure optimization, effective, for the sound and rapid economic and social development in our province has made great contribution.

The Scale of Higher Vocational Students in Yunnan has been Further Expanded

By the end of 2015, there were 41 independently higher vocational colleges and universities established in Yunnan province. 196000 students entered higher vocational college that is $31.89 \%$ of all Yunnan provincial college students. Vocational (specialized) the average size of 6228 full-time students. (The average size of vocational (specialized) has been 6228 of full-time students.)

The Government of Yunnan Province Keeps Increasing the Construction of Vocational Colleges

The government has increased funding for education, strengthened infrastructure construction and improved conditions for running schools and gradually increasing the strength of its schools. In the past three years, the funds of education have been kept at about 15,000 Yuan, and education expenditure of the state has been increasing rapidly, with an average annual growth rate of $10.97 \%$. The value of the teaching equipment of the whole province was 10,400 Yuan. The total area of teaching research and assistance and administrative office is 34.59 square meters. The provincial higher vocational colleges have basically realized the informational teaching and management.

\section{Characteristics of Higher Vocational Students in Yunnan and the Performance of Civilized Values.}

\section{Characteristics of Students in Higher Vocational Colleges in Yunnan}

Yunnan has 26 ethnic minorities, many mountainous areas, uneven regional economic and social development, and ethnic customs have unique forms in each region. (There are 26tehnic minorities 
in Yunnan province which contained many mountainous areas. Due to this, the development of regional economic and society is unbalanced. The ethnic customs get their unique forms in each region.) Higher vocational colleges are clustered in Kunming, the capital city of Yunnan province. Most higher vocational colleges students are natives, which determines the characteristics of higher vocational students in Yunnan.

Most Students come from Rural (villages) of Yunnan. According to the enrollment of a vocational college in Kunming in September 2017, 1,132 students are enrolled in vocational colleges, of which about 620 are ethnic minorities, and $90 \%$ of them are from rural areas. Under such conditions(circumstances), these vocational college students from Yunnan province are distinguished from the students of ordinary undergraduate vocational colleges.

The Students' Cultural Foundation is Generally Poor. Higher vocational students score is low. In 2017, the vocational college students admit fractional line is 300 points, 145 points compared with the ordinary undergraduate vocational colleges students less (which is 145 points lower than the ordinary undergraduate vocational colleges students), Higher vocational college students on the entrance scores are more, reflects the phase students poor cultural basis. (The disparity scores in college entrance examination reacting the poor culture basis on higher vocational college students.)

Self-conscious and Civilized Habits are Poor. In one class, there is a minority girls from some ethnic minority areas. While in the freshman year, and students away, do not obey the traffic rules, optional heap of garbage, spit at random, in the talk, the girl admitted that they were there are mountains and grassland, and no zebra crossing on the road, don't know how to obey the traffic rules, crossing the street and no trash can.(When she goes to the outside of campus, she doesn't obey the traffic rules in the freshman year. Her bad habits like this kind are more found by her classmates such as throw away the garbage optionally, spit at random etc. Once she discussed this with her classmates, she said that there were mountains and plants all around her home yard. The road didn't contain a zebra crossing lines and trash cans.) With the help of the dormitory students, the girl spent about one year on changing the bad habit of being unconscious and uncivilized.

The Irritable Impulse, the Obvious National Characteristic. Yunnan's ethnic majority mostly live in bad weather, terrain rugged mountain, so drinking is a natural habit for men and women. The sentence "men don't drink, white in the world" ( If a man doesn't drink any alcohol, his whole life is wasteful.) real reaction the characteristics of the Yunnan people love to drink (fanatical potty about the alcohol). For example, the Yi nationality (ethnic) and the Tibetan, the male begins to drink from an early age. If the guest arrives home, the door first drinks three bowls of wine. (the guest should drink three bowls of wine first.) As a higher vocational college student, after drinking, impulsive and irritable, often with people to quarrel and even fight, not only delay the study, but also not conducive to social harmony. ( As higher vocational college students, they are easily impulsive and irritable, even though causing quarrel and fight sometimes. These matters not only spoil their study, but also conducive to the society harmony.)

I don't know Myself. (Knowing them unclearly.) The life in my hometown for a long time, the influence of society, customs, said most of the higher vocational college students after graduation are hard to find a job in a big city, it is difficult to root in the provincial capital, they think learning knowledge is returned to the hometown, the farming farming, the farming land, such way of self-awareness to some extent, restricted the development of students. (With the long time influence of their life, environment and customs in their homes, piles of the Higher Vocational College students said that, it's difficult to find a job in big cities and root in the provincial capital. What they desired is going back to their hometown after finish their study as a farmer. To some extent, such kind of self-awareness restricted their career development.)

\section{Specific Forms of Vocational College Students}

In their study of life, I always go to extremes in overconfidence and excessive self-abasement, and I feel great emotional ups and downs. Sometimes I think I can do anything, and sometimes I feel that I can't do anything. (The students are usually overconfidence and excessive self-abasement, which always go to extremes and moving swings. Such as they feel they can counsel everything but sometimes can do nothing.) 
Do something that requires time and energy, but they are lack of basic patience and focus.

When problems and difficulties appears, they are not willing to face. I like (they tend) to find other reasons, and seldom find their shortcomings objectively.

Low mental capacity, fragile emotional vulnerability, lack of responsibility and responsibility;

The physiological age is not commensurate with the age of development, and it is characterized by inappropriate thoughts and behaviors;

Regardless of respect, arrogance and arrogance, students get along with each other more, unwilling to comply with the discipline and less willing to learn.

The Performance of High Vocational College Students' Civilized Values

Civilization is the sum of material achievements, political achievements and spiritual achievements made by mankind to transform the world. It is the status and symbol of social development and human progress. In the core values, "civilization" is the value target at the national level, which refers to the macro-sense, including the three great civilizations, as well as the concrete civic literacy. When it comes to civilization, what we often call "uncivilized" phenomena cannot be avoided. The national civilization quality, the public behavior norms or not, relations to the national image, national prestige. Yunnan higher vocational college students' civilization values mainstream is healthy, positive, but influenced by the social environment, diversified value orientation, such as economic development, there is also a part of the higher vocational college students values deviating from the phenomenon, mainly for the following:

The Subject of Values is Localized. Some students after admission, has kept in his hometown of habits, such as leisure, after school or festivals to drink, but as for colleges and universities is generally stop students from drinking in the school, so the students over the fence, want to wait for a phenomenon, the serious influence the students' learning. After admission, some students kept their hometown customs, such as drinking alcohol at leisure, after school and national festivals. But for a qualified college student, drinking should be forbidden in the school. So some students want to go over the fence to the outside even stay out all the night. This has an extremely bad influence for their daily study.

Habitual Thinking is Hard to Change. Yunnan's economic and social development lags behind, uneven regional development, most of the rural poor infrastructure, environment to a certain extent, affected the formation of their civilization and civilized values. Some backward area of higher vocational college students came to Kunming university, regional national habit difficult to change, not abide by the rules, dormitory considered the school rules, spitting, littering, and do not obey traffic rules through the highway at will. Any habitual form of thinking is the result of a long accumulation of time, and it takes a long time to change.

The Influence of National Characteristics is Far-reaching. Yunnan has 26 ethnic minorities, each of which has its own unique beliefs. Some students, a few people into classes, rest after school a loner, looking for our nation's hometown together over the weekend, this is very bad for the values of college students to cultivate.

\section{Yunnan Higher Vocational Students Civilization Value Promotion is the Inevitable Choice of Social Development}

"Young people should start from now, start from themselves, make socialist core values become their basic following, and vigorously promote it to the whole society." Why should I talk to the youth about the core socialist values? It is because the value orientation of youth determines the value orientation of the whole society in the future, while the youth is at a time when values are formed and established, and it is very important to grasp the values of this period. This is like wearing a cloth, but with the wrong order of button, if the first button is wrong, the rest of the buttons will be wrong. The buttons of life are buttoned up from the beginning. "Well, if you dig a well, you'll get up to three inches." Young people should start from now, start from themselves, make socialist core values become their basic following, and vigorously promote it to the whole society. Xi general secretary to all teachers and students in Beijing university symposium, to the country's young students request, fully shows that our country in the lead young students is an 
urgent need to establish and consolidate the correct values.

"On business trips abroad or at home, we often see uncivilized behavior by some Chinese people," said Yang min, a representative of the National People's Congress and chairman of hawing industrial group LTD. No one is rich; the head is still empty, civilized quality still cannot go up. It's time for massive modern citizen literacy. Ancient Rome in Italy, the Great Wall of China has left behind the Chinese tourists "so-and-so going on," the formation of the promotion of China's civilization quality and civilized values is the inevitable requirement of China's economic and social development.

\section{Further Strengthen Yunnan Higher Vocational College Students Civilization Value Cultivation} Way

\section{Establish Incentive Mechanism, Strengthen Government Propaganda and create a Favorable Social Environment}

In recent years, the public welfare propaganda of values such as traditional culture, civilized tourism and optical disk operation has not only been deeply rooted in the people's hearts, but also received the unanimous approval of the whole nation. Local governments at all levels should further introduce incentives and mechanisms, certain rewards for outstanding college students civilization behavior, sets up the model, especially in the higher vocational college students in college students groups to build a strong atmosphere of civilization with positive values.

\section{Higher Vocational Colleges should Carry out Specific Implementation to Guide Higher Vocational College Students to Establish Correct Civilized Values}

College is an important period for the formation and development of college students' values, and the school is the main position of education. Higher vocational college to improve the ideological and political education mechanism, set up to encourage civilized behavior of reward to encourage mechanism, appraisal and recognition on a regular basis, to build a set of the construction of campus culture, curriculum, teacher education, which integrates a full range of educational environment, a new civilization will be civilized values education lies in their study, life and scientific research work, truly ", "teaching, management and service,.

Establish a long-term Mechanism for Higher Vocational Colleges and Students' Families, and Further Promote the Consolidation of Civilized Values Among College Students

"The family is the first teacher of the students", home values of higher vocational college students civilization has a long and profound influence on the formation and development of the, family education is an important part in students' values education can not be ignored, civilized values based education role. The higher vocational colleges should establish a long-term mechanism to connect with students' families, strengthen communication regularly, and work closely with the school to establish the correct values of students' civilization. Students' learning and physical and mental health are not only the responsibility of the school, parents should also pay attention to their children's academic performance, and also pay attention to the quality of children's moral cultivation education. Parents should set an example to guide their children in a scientific, healthy and positive way of life, to enhance their sense of responsibility, sense of mission, study hard and build a country.

To Enhance the Values Education of Civilization, Aiming at the Characteristics and Individual Differences of Vocational College Students

Higher vocational college students values of civilization has its own characteristics, different regions, different nationalities, different family background, different professional, different grades of higher vocational college students' values of civilization there are differences. It is necessary to carry out civilized values education and guidance for the individual differences of higher vocational college students, and enhance the effect of education of civilized values.

First, establishing the correct life goal is the key to the cultivation of civilized values. Vocational college is trained to adapt to the production, construction, management of the first line of skilled talents, in the attention to the society, the market demand, and more attention to the student's own development; Guide the student to learn the correct analysis of the situation and self-understanding, 
ZunZhangShouJi and civility, treat their own shortcomings and deficiencies, correctly determine the development direction and goal, students are encouraged to improve self quality and accomplishment, strengthen students' confidence, reduce the blind and impulsive, help students to set a realistic goal in life.

Second, it is an important guarantee for the cultivation of civilized values to attach importance to the psychological health of education. Values education to psychological health education and civilization, civilization determined values education is the goal of higher vocational college students ideal, standard system, value orientation, etc., and mental health education is in order to maintain the perfection of personality and individual physical and mental health. Higher vocational colleges should actively carry out the psychological health education, strengthen the school psychological consultation work. For students in the development of individual learning, life, mood, emotion, employment and other issues for targeted psychological counseling and adjustment, help students to correctly understand and treat their own problems, find the methods to solve the problem, reduce psychological conflict and contradiction, build healthy and positive values.

Third, strengthening the education guidance of ideological and political courses is a necessary way to cultivate civilized values. Values with higher vocational college students is the important task of ideological and political education in higher vocational colleges, to marxism-leninism and formal education courses in higher vocational colleges in the curriculum, actively guide the student to set up civilization on thought, healthy, positive, and progressive values, and guide students to consciously practice, have the courage to explore, to read studious, think more good q, innovations, especially pay attention to civilization start from the intravenous drip, from nearby small start, practical, the school and the party's ideological and political education permeate all aspects of their daily study and life, strengthen the social value of behavior standards, through the practice value of repeated reinforcement, exercise keen mind, good judgment, and then establish the correct values and culture values in life, try to make their main social modernization construction of a new generation of successors.

\section{Acknowledgement}

Higher vocational colleges should combine era melodies, aimed at the characteristics of higher vocational college students and the law of development, comprehensive training, set up higher vocational college students' correct values of civilization, promote the all-round development of higher vocational college students.

\section{References}

[1] xi jinping, young people should conscientiously practice the core socialist values -- speech at the symposium of teachers and students of Peking University [R], May 5, 2014.

[2] xue Ming, the reasons for the formation of higher vocational students' values and the countermeasures of education [J],education and occupation, no. 33 (total 709) p68-70.

[3] liu congli, values education plays a role in improving the quality of students in higher vocational colleges [J],professional education, p142-143.

[4] Lu Aijun Xu Hongfei, research on the training of Higher Vocational Students' values, [J], Journal of Beijing Vocational College of Agriculture, Vol. twenty-eighth, third issue P104-108

[5] jiang qiuming,the development and analysis report of yunnan professional education [Z] 